\title{
Hepatitis B in Health Care Workers: Indian Scenario
}

\author{
Varsha Singhal, Dhrubajyoti Bora, Sarman Singh
}

Division of Clinical Microbiology, Department of Laboratory Medicine, All India Institute of Medical Sciences, New Delhi - 110 029, India

Address for correspondence: Prof. Sarman Singh, E-mail: sarman_singh@yahoo.com

\begin{abstract}
Healthcare workers have a high risk of occupational exposure to many blood-borne diseases including HIV, Hepatitis B, and Hepatitis $C$ viral infections. Of these Hepatitis B is not only the most transmissible infection, but also the only one that is preventable by vaccination. In developing countries, Hepatitis B vaccination coverage among healthcare workers is very low for various reasons, including awareness, risk assessment, and low priority given by the health managements of both government and private hospitals. Most of the hospitals lack post-exposure management strategies including the coordination among various departments for reporting, testing, and vaccination. This review, therefore, focuses on the current situation of Hepatitis B vaccine status in the healthcare workers of India, and provides updated guidelines to manage the accidental exposure to hepatitis $B$ virus-infected biological materials in healthcare workers. The review also emphasizes on what options are available to a healthcare worker, in case of exposure and how they can respond to the standard vaccination schedules, besides the need to educate the healthcare workers about Hepatitis B infection, available vaccines, post-vaccine immune status, and post-exposure prophylaxis.
\end{abstract}

Keywords: Healthcare worker, hepatitis B virus, HBsAg, vaccine, responders, non-responder, post-exposure prophylaxis

DOI: $10.4103 / 0974-2727.59697$

\section{INTRODUCTION}

O he first biomarker of the Hepatitis B virus (HBV) infection was discovered by Blumberg et al. in 1965 and was named as the, 'Australia antigen'. Subsequently, this biomarker was discovered to be the hepatitis B surface (HBsAg) antigen. Before the discovery of this antigen, hepatitis $B$ was diagnosed on the basis of infection occurring 60-180 days after the injection of human blood or plasma fractions or the use of inadequately sterilized needles. Hepatitis B is the only human representative of a family of DNA viruses of which related viruses have been found in woodchucks, Peking ducks, and ground squirrels. The virus is a double-stranded DNA virus, the positive strand is incomplete and replication involves a reverse transcriptase. The virus coat and the $22-\mathrm{nm}$, free particles contain surface antigen ( $\mathrm{HBs} \mathrm{Ag})$. There are at least four phenotypes of HBsAg namely adw, adr, ayw, and ayr. There are more than seven genotypes of the virus. It has not yet been possible to propagate the virus in a cell culture. ${ }^{[1-3]}$

Hepatitis B infection is one of the major public health problems globally and is the tenth leading cause of death. Worldwide, more than two billion of the population have evidence of past or recent $\mathrm{HBV}$ infection and there are more than 350 million chronic carriers of this infection. ${ }^{[1]}$ In India, HBsAg prevalence among the general population ranges from 2 to $8 \%$, which places India in an intermediate HBV endemicity zone, and India with 50 million cases is also the second largest global pool of chronic HBV infections. ${ }^{[1,4]}$ Among healthcare workers seroprevalence is two to four times higher than that of the general population.

\section{HOW TO DIAGNOSE HEPATITIS B VIRUS INFECTION?}

When a person is infected with $\mathrm{HBV}$, the first virological marker detectable in the serum is $\mathrm{HBsAg}$. It precedes the elevation of serum aminotransferase and clinical symptoms. In a majority of cases, $\mathrm{HBs} A g$ becomes undetectable one to two months after the onset of jaundice and rarely persists beyond six months. During the recovery phase, HBsAg becomes undetectable, while antibodies to HBsAg (Anti$\mathrm{HBs}$ ) become detectable in the serum and remain so 
indefinitely thereafter. In addition, anti-HBs antibody is the only detectable serological marker in those who successfully respond to hepatitis $\mathrm{B}$ immunization.

Hepatitis B core antigen ( $\mathrm{HBcAg})$ is an intracellular antigen that is not detectable in serum. Antibodies against $\mathrm{HBcAg}$ (anti-HBc), indicate a prior exposure to $\mathrm{HBV}$, irrespective of the current HBsAg status. IgM anti-HBc is the first antibody detectable in an acute HBV infection. Usually it becomes detectable within one month after the appearance of $\mathrm{HBsAg}$ and disappears within six months. IgG anti$\mathrm{HBc}$ is not a neutralizing antibody and remains detectable throughout the patient's life. ${ }^{[2]}$

The third sensitive marker is Hepatitis B-e antigen, which usually indicates active HBV replication and risk of transmission of infection to non-immune persons. The details of all the detectable serological markers and their interpretations are given in Tables 1 and 2.

\section{WHAT IS THE RISK OF HEPATITIS B VIRUS INFECTION IN HEALTHCARE WORKERS?}

Healthcare personnel (HCW) are defined as persons (e.g., employees, students, contractors, attending clinicians, public-safety workers, or volunteers) whose activities involve contact with patients or with blood or other body fluids from patients in a healthcare, laboratory, or public-safety setting. An exposure that might place HCWs at risk for HBV, HCV, or HIV infection is defined as a percutaneous injury (e.g., a needle-stick or cut with a sharp object) or contact with mucous membrane (of eyes, mouth, nose, etc.) or non-intact skin (e.g., exposed skin that is chapped, abraded, or afflicted with dermatitis) with blood, tissue, or other body fluids that are potentially infectious. ${ }^{[3,4]}$

HBV infection is a well-recognized occupational risk for an HCW. The risk of $\mathrm{HBV}$ infection is primarily related to the degree of contact with blood in the workplace and also to the hepatitis B-e antigen ( $\mathrm{HBeAg}$ ) status of the source person. Studies ${ }^{[5,6]}$ have shown that of the HCWs who sustained injuries from needles contaminated with blood containing HBV, the risk of developing clinical hepatitis is variable as shown in Table 3.

Although most of the HBV infections in healthcare workers are attributed to percutaneous exposure, in many studies, most infected HCWs could not recall any overt percutaneous injury. ${ }^{[3]}$ In addition, HBV has been demonstrated to survive in dried blood, at room temperature, on environmental surfaces, for a long time. Thus, HBV infections that occur in HCWs with no history of exposure might have resulted from direct or indirect blood or body fluid exposures that inoculated HBV into the mucosal surfaces or cutaneous scratches and other lesions. ${ }^{[5,6]}$ The potential for HBV transmission through contact with environmental surfaces has been demonstrated in investigations of HBV outbreaks among patients and staff of hemodialysis units. ${ }^{[7,8]}$

Blood contains the highest HBV titres of all body fluids and is the most important vehicle of transmission in the healthcare settings. HBsAg is also found in several other body fluids, including breast milk, bile, cerebrospinal fluid, feces, nasopharyngeal washings, saliva, semen, sweat, and synovial fluid. However, the concentration of HBsAg in body fluids can be 100-1000 folds higher than the concentration of infectious HBV particles. Therefore, most body fluids are not efficient vehicles of transmission because they contain low quantities of infectious $\mathrm{HBV}$, despite the presence of $\mathrm{HBsAg}$. Interestingly, $\mathrm{HBV}$ is more infectious than $\mathrm{HIV}$ and can survive in dry blood for at least one week. ${ }^{[3]}$

The risk of HCWs acquiring occupationally related HBV infection has been shown to be associated with several factors. Two important factors are the degree of exposure to the infected body fluids or blood-contaminated sharps such as needles and other medical instruments, and the duration of employment in an occupational risk category.

\begin{tabular}{|c|c|c|c|c|c|c|}
\hline Anti-HBc & $\mathrm{HBsAg}$ & HBeAg & Anti-HBe IgM & Anti-HBe IgG & Anti-HBs & Interpretation \\
\hline+ & + & - & - & - & - & Indicate that person is infected, but in the incubation period \\
\hline+ & + & - & + & + & - & Acute hepatitis B or persistent carrier state \\
\hline+ & + & - & - & + & - & Persistent carrier state \\
\hline+ & - & + & \pm & + & - & Persistent carrier state \\
\hline- & - & & \pm & + & + & Convalescence \\
\hline - & - & - & - & + & + & Recovery \\
\hline - & - & - & + & - & - & Infection with $\mathrm{HBV}$ without detectable $\mathrm{HBsAg}$ \\
\hline - & - & - & - & + & - & Recovery with loss of detectable anti-HBs \\
\hline - & - & - & - & - & + & $\begin{array}{l}\text { Immunization without infection. Repeated exposure to } \\
\text { antigen without infection }\end{array}$ \\
\hline
\end{tabular}




\begin{tabular}{|c|c|}
\hline \multicolumn{2}{|c|}{$\begin{array}{l}\text { Table 2: Common serological markers of HBV } \\
\text { infection }\end{array}$} \\
\hline Hepatitis B surface antigen (HBsAg) & $\begin{array}{l}\text { - General marker of the HBV infection } \\
\text { - First serologic marker to appear } \\
\text { - Persistence for more than } 6 \text { months } \\
\text { suggests chronicity }\end{array}$ \\
\hline $\begin{array}{l}\text { Antibody against Hepatitis B surface } \\
\text { antigen (Anti-HBs) }\end{array}$ & $\begin{array}{l}\text { - Neutralizing antibody } \\
\text { - Indicates recovery and/or immunity } \\
\text { - The only marker detectable after } \\
\text { immunity conferred by HBV } \\
\text { immunization }\end{array}$ \\
\hline Hepatitis B 'e' Antigen (HBeAg) & $\begin{array}{l}\text { - Indicative of active replication of the } \\
\text { virus and high risk of transmission }\end{array}$ \\
\hline $\begin{array}{l}\text { Antibody against Hepatitis B 'e' } \\
\text { antigen (Anti-HBe) }\end{array}$ & $\begin{array}{l}\text { - Indicates less active replication and } \\
\text { remission of disease }\end{array}$ \\
\hline $\begin{array}{l}\text { IgM antibody against Hepatitis B core } \\
\text { antigen (Anti-HBc) }\end{array}$ & $\begin{array}{l}\text { - Indicates acute HBV infection, } \\
\text { usually disappears within } 6 \text { months } \\
\text { - Approximately } 10-20 \% \text { of chronic } \\
\text { patients with reactivation or flares } \\
\text { will also show positive values }\end{array}$ \\
\hline $\begin{array}{l}\text { IgG Antibody against Hepatitis B core } \\
\text { antigen (Anti-HBC) }\end{array}$ & $\begin{array}{l}\text { - Presence indicates exposure } \\
\text { - Isolated IgG anti-HBc may indicate } \\
\text { occult HBV infection }\end{array}$ \\
\hline
\end{tabular}

\begin{tabular}{lcc}
\hline $\begin{array}{l}\text { Table 3: Risk of HBV infection in healthcare } \\
\text { workers in case of needle prick }\end{array}$ \\
\hline $\begin{array}{l}\text { Serological status } \\
\text { of the source }\end{array}$ & $\begin{array}{c}\text { Risk of developing } \\
\text { clinical hepatitis } \\
\text { (\%) }\end{array}$ & $\begin{array}{c}\text { Risk of developing } \\
\text { serological evidence } \\
\text { of HBV infection (\%) }\end{array}$ \\
HBsAg positive HBeAg positive & $22-31$ & $37-62$ \\
HBsAg positive HBeAg negative & $1-6$ & $23-37$ \\
\hline
\end{tabular}

For example, in a large seroprevalence study conducted at five hospitals in different parts of the United States, HCWs with frequent blood contact or with frequently reported needle sticks had an approximately two-fold higher prevalence of HBV infection than did other HCWs. ${ }^{[9]}$ Occupational groups with a higher risk of infection included, attending physicians and surgeons, medical and surgical house officers, laboratory technicians, blood bank workers, assistants in surgery and pathology, and nurse anesthetists. Groups with a low risk of infection (who may have had much patient contact, but few blood or needle-stick exposures) included, clerks, pharmacists, social workers, dieticians, and food service workers. Other studies have shown that among physicians and dentists, those in specialties with more frequent blood or needle-stick exposures (e.g., obstetrician-gynecologists, anesthesiologists, pathologists, oral surgeons) have a significantly elevated risk compared to those in specialities such as pediatrics or psychiatry. ${ }^{[10]}$ An additional risk factor for acquisition of HBV infection among HCWs is the underlying prevalence of $\mathrm{HBV}$ infection in the population. High prevalence of HBV in developing countries substantially increases the risk of occupational exposure. ${ }^{[3]}$

\section{EPIDEMIOLOGY OF HBV INFECTION IN HEALTHCARE WORKERS}

Viral hepatitis as an occupational hazard of medical and paramedical personnel first received major attention in American medical literature in 1949, with the report by Leibowitz et al., on a case of serum hepatitis in a blood-bank worker. ${ }^{[1]]}$ The New York State Workmen's Compensation Board ruled that the illness was a compensable occupational hazard. Several other publications appeared in close succession. Kuh and Ward ${ }^{[12]}$ described seven cases of hepatitis among workers of a pharmaceutical company preparing blood derivatives. Turmbull and Greiner ${ }^{[13]}$ listed 16 cases occurring in a three-year period among workers of four hospitals. All these authors stressed the hazard of infection associated with frequent manual contact with blood or blood products. Inadvertent needle pricks, cuts from broken glassware, and contamination of other small wounds of the hands were considered to be the most probable means of transmission.

Throughout the world, millions of healthcare professionals work in health institutions and it is estimated that 600,000 to 800,000 cut and puncture injuries occur among them per year, of which approximately $50 \%$ are not registered. ${ }^{[14]}$ According to the World Health Organization (WHO) the proportion of healthcare workers in the general population varied substantially from region to region $(0.2-2.5 \%)$, as did the average number of injuries per healthcare worker (0.2-4.7 sharp injuries per year). ${ }^{[14]}$ The annual proportion of healthcare workers exposed to blood-borne pathogens was $5.9 \%$ for $\mathrm{HBV}$, corresponding to about $66,000 \mathrm{HBV}$ infections in healthcare workers worldwide.

In developing countries, $40-65 \%$ of $\mathrm{HBV}$ infections in healthcare workers were attributable to percutaneous occupational exposure. By contrast, in developed countries, the attributable fraction for HBV was less than $10 \%$, largely because of immunization and postexposure prophylaxis. ${ }^{[15]}$ In a study done in Brazil, out of 474 dentists associated with the Regional Odontology Council, $10.8 \%$ were seropositive for HBsAg. ${ }^{[16]}$ In Korea, a study was performed at Sanggye Paik Hospital in 2003, in which 571 HCWs (56 physicians, 289 nurses, 113 technicians, and 113 aid-nurses), between 21 and 74 years of age, were included. The positivity rate for HBsAg was $2.4 \%{ }^{[17]}$ In another study in Japan, out of 141 dental workers, it was found that no worker was HBsAg positive. ${ }^{[18]}$ This indicated that vaccination of healthcare workers and adoption of universal precautions in developed countries pays its dividends. As far as India is concerned the prevalence of hepatitis $\mathrm{B}$ in HCWs 
was reported to be $10 \%$ in 1992 , in one study, ${ }^{[19]}$ and $2.21 \%$ in another study done in $1998 .{ }^{[20]}$ More recently, in a tertiary care hospital in Delhi reported that only $1 \%$ of healthcare workers were $\mathrm{HBsAg}$ positive. ${ }^{[21]}$ Numerous sero-prevalence studies have shown that risk of contracting hepatitis B by healthcare workers is four times higher than that of the general adult population.

\section{HEPATITIS B VACCINATION COVERAGE LEVELS AMONG HEALTHCARE WORKERS}

Estimates of Hepatitis B vaccine coverage among healthcare workers are needed to calculate the proportion susceptible to $\mathrm{HBV}$ infection. According to the WHO estimates, it varies from $18 \%$ in Africa to $77 \%$ in Australia and New Zealand. ${ }^{[15]}$ In United States, $75 \%$ of the HCWs at risk had received three or more doses of hepatitis B vaccine. ${ }^{[22]}$ Similarly, in Sweden, the number of HCWs who have received at least one dose is $79 \%$, but only $40 \%$ were reported to be fully vaccinated. ${ }^{[23]}$ In Japan, vaccination coverage was found to be $48.2 \%$ in dental workers. ${ }^{[18]}$ In one study done in a tertiary care hospital, in Delhi, 55.4\% were reportedly vaccinated against Hepatitis B. ${ }^{[21]}$ However, the data was not explicit to describe the number of vaccine doses. Of late, we carried out a prospective study to evaluate the vaccination rate at the All India Institute of Medical Sciences, the premier medical institute of North India, and found that $52-59 \%$ of healthcare workers, in different categories, had taken hepatitis vaccine (unpublished data, details not shown here). This indicated that there was a moderately good awareness and vaccination programs in Delhi hospitals.

\section{POST-EXPOSURE PROPHYLAXIS}

After a healthcare worked gets exposed to potentially HIV-infected body fluid, there are a series of steps that should be taken by the concerned hospital. These include immediate initiation of post-exposure prophylaxis, risk assessment, and counseling. The PEP for HBV is slightly different from the PEP for HIV, and it may include active and passive immunization as well as drug treatment.

\section{Immediate treatment of the exposure site}

For percutaneous exposure, encourage bleeding and wash with soap and water. For mucous membrane contamination, flush only with water. Eyes should be washed with clean water or saline. There is no need for any antiseptics/disinfectants; their use is not contraindicated, except for eyes.

\section{Risk assessment}

The exposure site should be evaluated for the type of body fluid involved, and the route and severity of exposure. It is also advisable to evaluate the source patient's sero-status for $\mathrm{HIV}, \mathrm{HCV}$ antibodies, and for $\mathrm{HBsAg}$. Direct virus assays (e.g., HBV-DNA or HCV-RNA/HCV Ag) are not recommended. The blood samples of the exposed HCW must be collected as early as possible to check the baseline HBV, HCV, HIV immune status.

\section{Post-exposure prophylaxis}

Post-exposure prophylaxis with $\mathrm{HBV}$ vaccine, hepatitis B immunoglobulin (HBIG) or both must be started as soon as possible, preferably within 24 hours of the exposure and no later than one week. ${ }^{[24]}$ The decision to administer either only active immunization (HBV vaccine) or both active and passive immunization (HBIG) will depend on the risk assessment and score of the exposure. Those who have previously been infected with HBV are immune to re-infection and do not require post-exposure prophylaxis. If $\mathrm{HBIG}$ needs to be given, as described earlier, the dose should be adjusted to $0.06 \mathrm{~mL} / \mathrm{kg}$ intramuscularly. The immune response to the vaccine in the HCW must be assessed one to two months after the last dose of vaccine. In pregnant $\mathrm{HCW}$ also, the management remains same. ${ }^{[25]}$ A systemic flow chart for PEP with step by step details is given in Figure 1.

\section{PREVENTION OF HEPATITIS B VIRUS INFECTION AMONG HEALTHCARE WORKERS}

Prevention of exposure is the primary strategy to reduce the risk of occupational blood-borne pathogen infections in healthcare workers. All measures should be taken to prevent HCWs from infection. Also they should be made aware of the importance of reporting an exposure, and they should have ready access to expert consultants to receive the appropriate counseling, treatment, and follow-up. Vaccination against $\mathrm{HBV}$ and demonstration of immunization before employment are strongly recommended.

There are some important steps for minimizing the risk of $\mathrm{HBV}$ infection in $\mathrm{HCWs}$, which include, (a) that all HCWs be educated regarding the inherent risks in case of occupational exposure and their prevention, (b) they should be encouraged to adopt standard precautions, to use safety devices and other personal protective equipments, (c) they must be educated about safer procedures and proper vaccinations for all

Journal of Laboratory Physicians / Jul-Dec 2009 / Vol-1 / Issue-2 


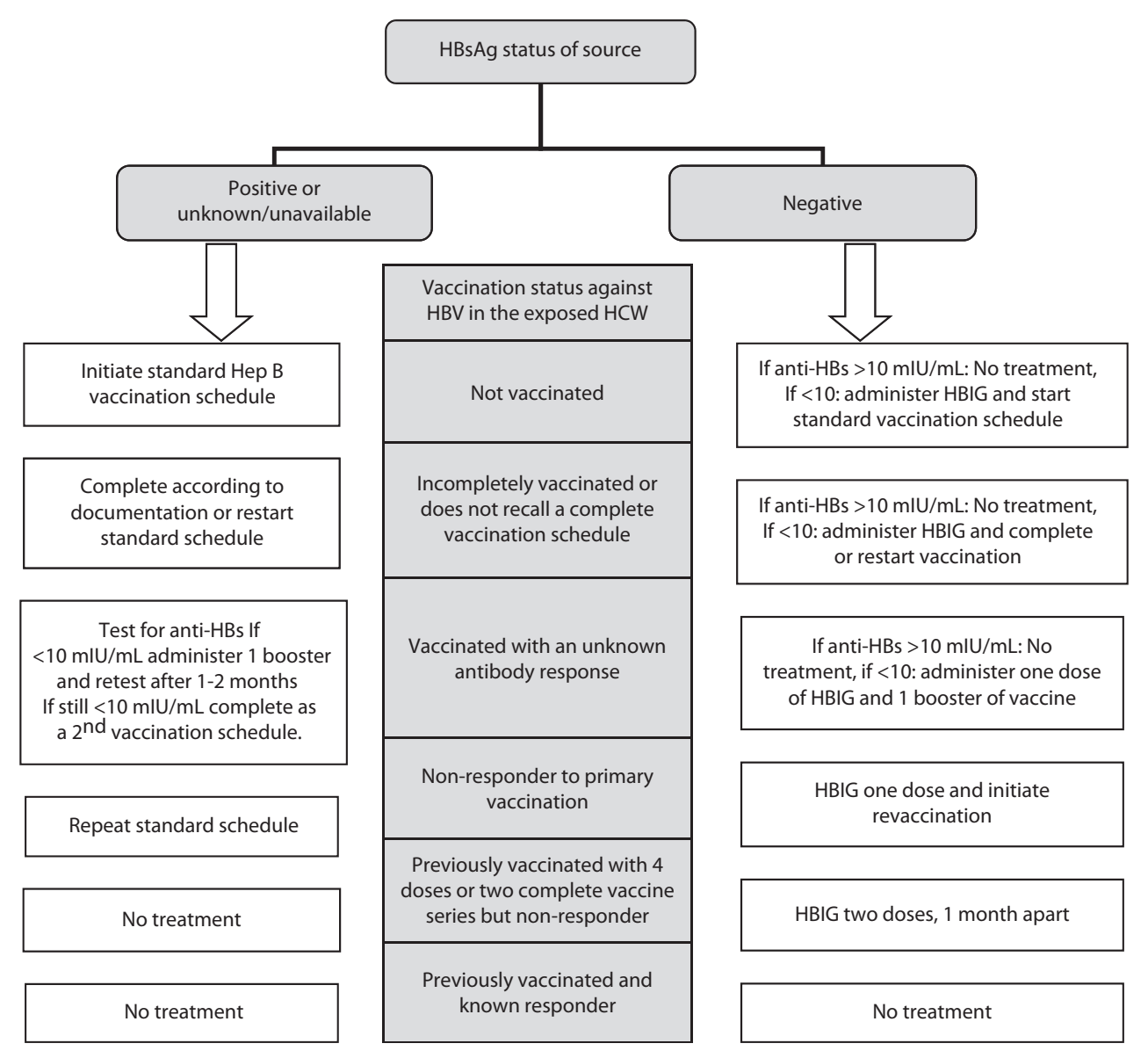

Figure 1: Post-exposure prophylaxis of hepatitis B infection

HCWs, and (d) post-exposure management must be put in place in hospital settings so that it can be centrally initiated, promptly, as and when required. Similar to HIV prophylaxis there must be a centralized counseling, testing, vaccination, and treatment facility that is widely advertised, and the location and contact numbers must be displayed at most visible sites of the hospital premises and made available round the clock.

\section{Reporting an occupational exposure}

As mentioned in the earlier section, there should be a designated healthcare provider to whom HCWs can urgently be referred in case of any exposure, and the person should be responsible for post-exposure management and coordinating the vaccination, testing, drug procurement, and so on. He will also take care of the provision of prophylaxis and clinical and serological follow-up. HCWs should also be made aware, in advance, of the medicolegal and clinical importance of reporting an occupational exposure, how to report it, and to whom it should be reported.

\section{Hepatitis B virus vaccination}

The most important approach for the prevention of occupational $\mathrm{HBV}$ infection is the use of hepatitis $B$ vaccine among HCWs at risk. Hepatitis $B$ vaccine has been available since 1981. During 2000-2004, self-reported hepatitis B vaccination coverage among adults at risk for $\mathrm{HBV}$ infection increased from $30 \%$ in 1981 to $45 \% ;^{[27]}$ this increase in vaccination coverage probably contributed to the $35 \%$ decline (from 3.7 to 2.4 per 100,000 population) in acute hepatitis B incidence during this period. Therefore, it is well-established that the HBV vaccine is highly protective and that any person who performs tasks involving contact with blood, bloodcontaminated body fluids, or sharps should be vaccinated against hepatitis B. ${ }^{[27]}$ All HCWs should be vaccinated against HBV, with a standard vaccination schedule. ${ }^{[29]}$ Three standard doses of recombinant $\mathrm{HBV}$ vaccine should be administered intramuscularly in the deltoid region, preferably with a 1-1.5 inch long needle at a 0,1 , and 6 month schedule.

Protection (defined as Anti-HBs level $\geq 10 \mathrm{mIU} / \mathrm{ml}$ ) following first, second, and third doses of the recombinant 
vaccine has been reported to be $20-30 \%, 75-80 \%$, and $90-95 \%$, respectively. ${ }^{[27,30-32]}$ There is no contraindication to administer other vaccines, and hepatitis $B$ vaccine can be administered at the same time as other vaccines, with no interference from the antibody response to other vaccines. If the vaccination series is interrupted after the first dose, the second dose should be administered as soon as possible. The second and third doses should be separated by an interval of at least two months. If only the third dose is delayed, it should be administered whenever convenient. ${ }^{[3]}$

In most of the western states, it is advised that before entering nursing and medical schools and before employment in healthcare settings, vaccination or demonstration of immunization against HBV must be recorded for legal and medical reasons, and if not immunized, they need to be vaccinated. ${ }^{[32]}$ Even though pre-vaccination screening is not routinely indicated, in some countries $\mathrm{HBV}$ vaccine can be combined with hepatitis A vaccine.

Although serologic testing for immunity is not necessary after routine vaccination of adults, post-vaccination testing is recommended for persons whose subsequent clinical management depends on the knowledge of their immune status, including certain healthcare and public safety workers; chronic hemodialysis patients, HIV-infected persons, and other immunocompromised persons; and sex or needle-sharing partners of $\mathrm{HBsAg}$-positive persons. ${ }^{[27]}$ Vaccinees can show their immune response differently. They respond well and are known as Responders. These subjects are those who mount post-vaccination anti-HBs levels of $\geq 10 \mathrm{mIU} / \mathrm{ml}$, when determined one to two months after the last dose of vaccine. The other group is known as Nonresponders. These are subjects who do not mount a satisfactory immune response after vaccination and the post-vaccine anti-HBs levels remain $<10 \mathrm{mIU} / \mathrm{ml}$, even after two months of the last dose of vaccine and test negative for $\mathrm{HBs} \mathrm{Ag}$ and anti-HBc antibodies. ${ }^{[26]}$

\section{Post-vaccination management}

- Responders are protected against HBV infection even if anti-HB concentrations subsequently decline to $<10 \mathrm{mIU} / \mathrm{mL}$. ${ }^{[27,33]}$ The mechanism for continued vaccine-induced protection is thought to be the preservation of immune memory through selective expansion and differentiation of clones of antigen specific $\mathrm{B}$ and $\mathrm{T}$ lymphocytes. ${ }^{[27]}$

- Routine booster doses of HBV vaccine are not recommended for known responders, even if anti-HBs levels become low or undetectable. ${ }^{[34]}$
- Periodic antibody concentration testing after completion of the vaccine series and assessment of the response is not recommended. ${ }^{[3]}$

- It is a fact that $5-10 \%$ of the adult population will not respond to standard $\mathrm{HBV}$ vaccination. ${ }^{[2]}$

- Risk factors for vaccine non-response include: Male sex, older age, cigarette smoking, obesity, immunodeficiency, chronic diseases, certain HLA haplotypes, and celiac disease. ${ }^{[35,36]}$

The non-responders who tested negative for HBsAg and anti-HBc: Should be,

- Administered a fourth dose and then retested after two months, for immune response. ${ }^{[37]}$

- If no response is elicited again, the full course of conventional vaccine at the standard doses (i.e., administration of a fifth and sixth dose) must be completed, and again the HCW must be retested for response, one to two months after the last dose of vaccine. ${ }^{[37,38]}$

- There are other possible alternative strategies to overcome non-response to standard HBV vaccination, but they need further evaluation. These include

- Immunization with vaccines containing $S$ subunit, pre-S1 and pre-S2 particles. ${ }^{[39,40]}$

- Three intra-dermal $5 \mu \mathrm{g}$ doses of standard vaccine to be given every two weeks. ${ }^{[41]}$

- Combined hepatitis A and hepatitis B vaccines are given, which might have a synergistic effect and mount an immune response, ${ }^{[42]}$ or

- A high-dose standard vaccination schedule is given. ${ }^{[38,43,44]}$

Chances of responding to a second three-dose schedule is reported to be highly encouraging, between $30-50 \%{ }^{[45]}$ Those who prove to be HBsAg-positive should be counseled on how to prevent HBV transmission to others, and also on the need for medical evaluation and treatment. ${ }^{[46,47]}$ Non-responders to vaccination, who are HBsAg-negative, should be considered susceptible to HBV infection and should be counseled on the precautions to prevent $\mathrm{HBV}$ infection and the need to obtain HBIG prophylaxis for any known or probable parenteral exposure to $\mathrm{HBs} A g$-positive blood, if such a situation arises.

\section{CONCLUSION}

The risk of hepatitis B infection is well documented among healthcare workers. Although with the use of hepatitis B vaccine the incidence of HBV infection in HCWs has decreased, there is still substantial scope for improvement, 


\section{Singhal, et al.: Hepatitis B in healthcare workers}

as many healthcare workers are unvaccinated. Therefore, there is a need for well-planned and clear policies for HBV screening and vaccination in healthcare workers, especially those who are at a greater risk of exposure to blood or other potentially infectious material.

\section{REFERENCES}

1. WHO. Hepatitis B: WHO/CDS/CSR/LYO/2002.2: Hepatitis B. Available at: http://www.who.int/csr/disease/hepatitis/whocdscsrlyo20022/en/ print.html [last accessed on 2009 Nov 9]

2. Kao JH. Diagnosis of Hepatitis B Virus Infection: Serological Diagnosis of HBV Infection. Medscape Today. Expert Rev Gastroenterol Hepatol 2008;2:553-62.

3. US Public Health Service. Centers for Disease Control and Prevention. Updated U.S. Public Health Service Guidelines for the Occupational Exposures of HBV, HCV, and HIV and Recommendations for Postexposure Prophylaxis. MMWR 2001:50;1-52.

4. Gupta S, Gupta R, Joshi YK, Singh S. Role of horizontal transmission in hepatitis B virus spread among household contacts in north India. Intervirology 2008;51:7-13.

5. Werner BG, Grady GF. Accidental hepatitis-B-surface-antigen-positive inoculations: Use of e antigen to estimate infectivity. Ann Intern Med 1982;97:367-9.

6. Lauer JL, vanDrunen NA, Washburn JW, Balfour HH Jr. Transmission of hepatitis B virus in clinical laboratory areas. J Infect Dis 1979;140:513-6.

7. Hennekens $\mathrm{CH}$. Hemodialysis-associated hepatitis: An outbreak among hospital personnel. JAMA 1973;225:407-8.

8. Garibaldi RA, Forrest JN, Bryan JA, Hanson BF, Dismukes WE. Hemodialysis-associated hepatitis. JAMA 1973;225:384-9.

9. Hadler SC, Doto IL, Maynard JE, Smith J, Clark B, Mosley J, et al. Occupational risk of hepatitis B infection in hospital workers. Infect Control 1985;6:24-31.

10. West DJ. The risk of hepatitis B infection among health professionals in the United States: A review. Am J Med Sci 1984;287:26-33.

11. Leibowitz S, Greenwald L. Serum hepatitis in a blood bank worker. JAMA 1949;140:1331-3.

12. Kuh C, Ward WE, Occupational virus hepatitis. JAMA 1950;143:631-5.

13. Trumbull ML, Greiner DJ. Homologous serum jaundice: An occupational hazard to medical personnel. J Am Med Assoc 1951;145:965-7.

14. EPINET. Needle-stick prevention devices. Health Devices 1999;28:381-407.

15. Hutin Y, Hauri A, Chiarello L, Catlin M, Stilwell B, Ghebrehiwet T, et al. Injection Safety Best Practices Development Group. Best infection control practices for intradermal, subcutaneous, and intramuscular needle injections. Bull World Health Organ 2003;81:491-500.

16. Batista SM, Andreasi MS, Borges AM, Lindenberg AS, Silva AL, Fernandes TD, et al. Seropositivity for hepatitis B virus, vaccination coverage, and vaccine response in dentists from Campo Grande, Mato Grosso do Sul, Brazil. Mem Inst Oswaldo Cruz 2006;101:263-7.

17. Shin BM, Yoo HM, Lee AS, Park SK. Seroprevalence of Hepatitis B Virus among healthcare workers in Korea. J Korean Med Sci 2006;21:58-62.

18. Nagao $Y$, Matsuoka H, Kawaguchi T, Ide T, Sata M. HBV and HCV infection in Japanese dental care workers. Int J Mol Med 2008;21:791-9.

19. Elavia AJ, Banker DD. Hepatitis B virus infection in hospital personnel. Natl Med J India 1992;5;265-8.

20. Kumar KA, Baghal PK, Shukla CB, Jain MK. Prevalence of hepatitis B surface antigen ( $\mathrm{HBsAg}$ ) among Health Care Workers. Indian J Comm Med 2000;25:93-6.

21. Sukriti, Pati NT, Sethi A, Agrawal K, Agrawal K, Kumar GT, et al. Low levels of awareness, vaccine coverage, and the need for boosters among healthcare workers in tertiary care hospitals in India. J Gastroenterol Hepatol 2008;23:1710-5.

22. Simard EP, Miller JT, George PA, Wasley A, Alter MJ, Bell BP, et al. Hepatitis $B$ vaccination coverage levels among healthcare workers in the
United States, 2002-2003. Infect Control Hosp Epidemiol 2007;28;783-90.

23. Dannetun E, Tegnell A, Torner A, Giesecke J. Coverage of hepatitis B vaccination in Swedish healthcare workers. J Hosp Infect 2006;63:201-4.

24. Weinbaum C, Lyerla R, Margolis HS; Centers for Disease Control and Prevention. Prevention and control of infections with hepatitis viruses in correctional settings. MMWR Recomm Rep 2003;52:1-36.

25. Mirza A, Wyatt M, Begue RE. Infection control practices and the pregnant health care worker. Pediatr Infect Dis J 1999;18:18-22.

26. Puro V, de Carli G, Cicalini S, Soldani F, Balslev U, Begovac J, et al. European recommendations for the management of healthcare workers occupationally exposed to hepatitis B virus and hepatitis C virus. Euro Surveill 2005;10:260-4.

27. Mast EE, Weinbaum CM, Fiore AE, Alter MJ, Bell BP, Finelli L, et al. Centers for Disease Control and Prevention (CDC). A Comprehensive Immunization Strategy to Eliminate Transmission of Hepatitis B Virus Infection in the United States: Recommendations of the Advisory Committee on Immunization Practices (ACIP) Part II: Immunization of Adults. MMWR Recomm Rep 2006;55:1-33.

28. Williams WW, Strikas RA, Alter MJ. Centers for Disease Control and Prevention (CDC). Immunization of Health-Care Workers: Recommendations of the Advisory Committee on Immunization Practices (ACIP) and the Hospital Infection Control Practices Advisory Committee (HICPAC). MMWR Recomm Rep 1997;46:1-42.

29. Poland GA, Jacobson RM. Clinical practice: Prevention of hepatitis B with hepatitis B vaccine. N Engl J Med 2004;351;2832-8

30. FitzSimons D, François G, de Carli G, Shouval D, Prüss-Ustün A, Puro V, et al. Hepatitis B virus, hepatitis C virus and other bloodborne infections in healthcare workers: Guidelines for prevention and management in industrialised countries. Occup Environ Med 2008;65:446-51.

31. Cornberg M, Protzer U, Dollinger MM, Petersen J, Wedemeyer H, Berg T, et al. German Society for Digestive and Metabolic Diseases; German Society for Pathology; Society for Virology; Society for Pediatric Gastroenterology and Nutrition; Competence Network for Viral Hepatitis. The German guideline for the management of hepatitis $B$ virus infection: Short version. J Viral Hepat 2008;15:1-21.

32. Averhoff F, Mahoney F, Coleman P, Schatz G, Hurwitz E, Margolis H. Immunogenicity of hepatitis B vaccines. Implications for persons at occupational risk of hepatitis B virus infection. Am J Prev Med 1998;15:1-8.

33. Durlach R, Laugas S, Freuler CB, Rodriguez VE, Costa M. Ten-year persistence of antibody to hepatitis $B$ surface antigen in healthcare workers vaccinated against hepatitis $B$ virus, and response to booster vaccination. Infect Control Hosp Epidemiol 2003;24:773-6.

34. European Consensus Group on Hepatitis B Immunity. Are booster immunisations needed for lifelong hepatitis B immunity? Lancet 2000;355:561-5.

35. Kubba AK, Taylor P, Graneek B, Strobel S. Non-responders to hepatitis B vaccination: A review. Commun Dis Public Health 2003;6:106-12.

36. Noh KW, Poland GA, Murray JA. Hepatitis B vaccine nonresponse and celiac disease. Am J Gastroenterol 2003;98:2289-92.

37. Struve J, Aronsson B, Frenning B, Forsgren M, Weiland O. Seroconversion after additional vaccine doses to non-responders to three doses of intradermally or intramuscularly administered recombinant hepatitis B vaccine. Scand J Infect Dis 1994;26:468-70.

38. Poland GA. Hepatitis B immunizaton in health care workers: Dealing with vaccine nonresponse. Am J Prev Med 1998;15:73-7.

39. Zuckerman JN, Sabin C, Craig FM, Williams A, Zuckerman AJ. Immune response to a new hepatitis $B$ vaccine in healthcare workers who had not responded to standard vaccine: Randomised double blind dose-response study. BMJ 1997;314:329-33.

40. Zuckerman JN. Hepatitis B third-generation vaccines: Improved response and conventional vaccine non-response- - third generation pre-S/S vaccines overcome non-response. J Viral Hepat 1998;5:13-5.

41. Playford EG, Hogan PG, Bansal AS, Harrison K, Drummond D, Looke DF, et al. Intradermal recombinant hepatitis B vaccine for healthcare workers who fail to respond to intramuscular vaccine. Infect Control Hosp Epidemiol 2002;23:87-90

42. Nothdurft HD, Zuckerman J, Stoffel M, Dieussaert I, van Damme P. Accelerated vaccination schedules provide protection against hepatitis A and B in last-minute travelers. J Travel Med 2004;11:260-1. 
43. Kim MJ, Nafziger AN, Harro CD, Keyserling HL, Ramsey KM, Drusano GL, et al. Revaccination of healthy nonresponders with hepatitis B vaccine and prediction of seroprotection response. Vaccine 2003;21:1174-9.

44. Bertino JS Jr, Tirrell P, Greenberg RN, Keyserling HL, Poland GA, Gump D, et al. A comparative trial of standard or high-dose $\mathrm{S}$ subunit recombinant hepatitis B vaccine versus a vaccine containing $S$ subunit, pre-S1, and pre-S2 particles for revaccination of healthy adult nonresponders. J Infect Dis 1997;175:678-81.

45. Hadler SC, Francis DP, Maynard JE, Thompson SE, Judson FN, Echenberg DF, et al. Long-term immunogenicity and efficacy of hepatitis B vaccine in homosexual men. N Engl J Med 1986;315:209-14.
46. Centers for Disease Control and Prevention. Recommendations for preventing transmission of human immunodeficiency virus and hepatitis $\mathrm{b}$ virus to patients during exposure-prone invasive procedures. MMWR Recomm Rep 1991;40:1-9.

47. Unanimous. Centers for Disease Control and Prevention. Public Health Service Inter-Agency Guidelines for Screening Donors of Blood, Plasma, Organs, Tissues, and Semen for Evidence of Hepatitis B and Hepatitis C. MMWR Recomm Rep 1991;40 (RR-4):1-17.

Source of Support: Nil, Conflict of Interest: None declared.

\section{Author Help: Online submission of the manuscripts}

Articles can be submitted online from http://www.journalonweb.com. For online submission, the articles should be prepared in two files (first page file and article file). Images should be submitted separately.

1) First Page File:

Prepare the title page, covering letter, acknowledgement etc. using a word processor program. All information related to your identity should be included here. Use text/rtt/doc/pdf files. Do not zip the files.

\section{2) Article File:}

The main text of the article, beginning with the Abstract to References (including tables) should be in this file. Do not include any information (such as acknowledgement, your names in page headers etc.) in this file. Use text/rtf/doc/pdf files. Do not zip the files. Limit the file size to $1 \mathrm{MB}$. Do not incorporate images in the file. If file size is large, graphs can be submitted separately as images, without their being incorporated in the article file. This will reduce the size of the file.

3) Images:

Submit good quality color images. Each image should be less than 2048 kb (2 MB) in size. The size of the image can be reduced by decreasing the actual height and width of the images (keep up to about 6 inches and up to about 1200 pixels) or by reducing the quality of image. JPEG is the most suitable file format. The image quality should be good enough to judge the scientific value of the image. For the purpose of printing, always retain a good quality, high resolution image. This high resolution image should be sent to the editorial office at the time of sending a revised article.

4) Legends:

Legends for the figures/images should be included at the end of the article file. 